\title{
COMPARITIVE STUDY ON THE EFFECT OF RHOZOBIUM INOCULUM ON IMBIBED SEEDS AND GERMINATED SEEDS OF VIGNO MUNGO L.
}

\section{O.N.Shanmugapriya and S.Priya*}

P.G and Research Department of Microbiology, S.T.E.T. Women's College, Mannargudi, T.Nadu, India

P.G Department of Biotechnology, S.T.E.T. Women's College, Mannargudi, T.Nadu, India Corresponding Author: piri_333@yahoo.co.in, +91 9787392903

\section{ABSTRACT}

The Rhizobium was isolated from the plant root and purified. The isolated rhizobium sample was identified based on morphological and bio chemical characterization. The result of biochemical tests showed positive result in indole test, citrate utilization test,starch hydrolysis test, urea hydrolysis test and catalase test. The isolated culture was mass multiplied and used by seed treatment like imbibed treatment and germinated treatment. After treatment the seedlings per planted separately by part culture method. The result showed that the rhizobium inoculation on the emerging radicals of one day old seedling is highly effective in nodulation and biomass production respectively.

Key words: YEMA medium;Vigno mungo; Germinated seed; biochemical test.

\section{Council for Innovative Research}

Peer Review Research Publishing System

Journal of Advances in Natural Sciences

Vol. 3, No. 1

editorjansonline@gmail.com 


\section{INTRODCUTION}

Nitrogen is one of the major important nutrients very essential for crop growth. But the availability of this element in soil is naturally deficient (Bras et al., 2000).so the nitrogen requirements of crop plants met by the addition of fertilizer nitrogen. Fertilizer nitrogen application often commonly increase agricultural yields but these fertilizers also associated with the population of water resources declining yields and greenhouse gas emission. Our challenge is to develop and disseminate technologies which conserve natural resources while they enhance agricultural productivity and human welfare.

In soil, a number of microorganisms are at work in fixing atmospheric nitrogen. Microbial fixation of nitrogen is carried out by free living and symbiotic groups of microorganisms play an important role in agricultural soil as well as forest soil. Leguminous crops or leguminous forest plants can obtain most of nitrogen they need from the vast supply of gaseous nitrogen in the air. Legume plants fix and utilize this nitrogen by working symbiotically with special bacteria called Rhizobium in nodules on their roots (Chandra,1991).

Non-legumes are known to develop nodules and to accommodate symbiotic nitrogen fixation. While the potential for nitrogen fixation is directly related to the rhizobial survival, the extent of effective nodulation and the plant growth factors (Gandhi and Godbole, 1990). However, some strains of the native soil population infect the roots but are not able to fix nitrogen, while other native strains fix nitrogen but often not as efficiently as the specially selected strains used in commercial inoculants or through the natural selection (Ghalab et al., 2000). The present study was undertaken with the view to comparative study on the effect of Rhizobium inoculation on imbedded seeds and germinated seeds of Black gram (Vigno mungo L.).

\section{MATERIALS AND METHODS}

\section{Plant material}

Vigno mungo coming under the family Fabaceae, is a short duration commercial pulse crop. The relevance of this plant is used as multipurpose cooking item and the leaves have medicinal properties. The plant involved in the nitrogen fixation process (Kulhare et al., 1996)) and used as delicious fodder.

\section{Collection of nodules}

Around the Devaram nagar in Thanjavur (Vigno mungo) plants were dug out at flowering stage. Large sized pink nodules were collected by uprooting the plants with intact root system. The nodules were brought to the laboratory for the isolation of rhizobia.

\section{Isolation of Rhizobium}

For the isolation of Rhizobium from the root nodules, the method described by Vincent (1970) has been followed.

\section{Characterization of Rhizobium isolate}

The isolates of rhizobia were confirmed for their identify by growth of congored yeast extract, staining of polyhydroxyl butyrate and growth of YEMA medium containing bromo phenol blue.

\section{Cultural characteristics of Rhizobium (Lazzo and Wopereis, 2000)}

The rhizobial isolates were grown on YEMA medium, after 24 hrs the colony shape and size (diameter) of the rhizobial isolates were measured and recorded.

\section{Mass cultivation of Rhizobium}

The isolated rhizobial strain was cultures in YEMA medium for about 3 days in order to establish better growth of bacteria. Three to six days old cultures of Rhizobium was examined for purity and the bacterial colonies were scraped with the help of an inoculation needle and was transferred to $250 \mathrm{ml}$ conical flask containing YEMA broth. The subculture flasks were incubated at $28^{\circ} \mathrm{C}$ on rotary shaker for $2-3$ days.

\section{Experimental design (Poonam Chaudhary et al., 2002)}

Garden soil was initialy sieved and then sterilized in an autoclave at $15 \mathrm{lb}$ pressure for $15-20 \mathrm{~min}$. Then the soil was sprinkled with water and mixed to field capacity. Then the pots were filled with the soil and labeled. For culture comprised of one control sterilized soil and one imbibed seed one geminating seed with three replications were conducted. 


\section{Parameters analysis}

\section{Total number of root nodules} respectively.

Total number of nodules, total biomass and total root biomass were analyzed and expressed in number and gram

\section{RESULT AND DISCUSSION}

In the present study rhizobium was isolated by root nodules of legume plant Vigno mungo .The isolates were purified and showed positive result in PHB test and failed to congo red in YEMA coloration was not found in lactose agar test, 3- keto lactose test and no growth was found in Hofer's alkaline agar and litmus milk reaction test of rhizobial isolates.

Many workers surveyed (Poornina Yada, 2004) many strains of rhizobial and used many cultural test, pointed out that the rhizobia typically show slow growth on peptone glucose agar, form little or no $\mathrm{H}_{2} \mathrm{~S}$ from bismuth sulphite and no precipitate in glycerol phosphate agar, not absorb in congo red from YEMA medium, unable to grow.

The isolated culture were identified by various morphological and biochemical method. The result clearly indicate all the rhizobium were gram-negative, rod shaped and motile in nature the cell and diameter of rhizobial isolates ranged from 0.5 to $3 \mu \mathrm{m}$ respectively. The result of biochemical test such as indole test, citrate utilization test, starch hydrolysis test, urea hydrolysis test and catalase test showed all the positive result in all the rhizobial isolates, were all the isolates showed the negative result in methyl red test, VP test, triple sugar iron test and oxidase (Table-1).

Rhizobium inoculams on emerging radical of Phaseolus mungo is highly effective in nodulation and biomass production when compared to inoculation on imbedded seeds. Application of Rhizobium culture directly on the seed surface before sowing can improve the nodule development and biomass production (Yousif and Sprent, 1983).

The isolated culture was mass multiplied using YEMA broth. The culture was used by seed treatment. Two type of seed treatment was carried out after treatment the imbibed and young seedlings were planted separately in pot under uniform conditions of soil mixture and temperature.

Rhizobium inoculated plants showed nodules on $20^{\text {th }}, 30^{\text {th }}, 40^{\text {th }}$ and $50^{\text {th }}$ day of planting (table-2) indicate the total biomass production in control and rhizobium inoculated Vigno mungo seeds. The rhizobium inoculation on the emerging radicals of one day old seedlings is highly effective in nodulation and biomass production. When compared to the plant developed from rhizobium imbibed seeds, plant from rhizobium inoculated seedlings recorded about $100 \%$ increase in nodule development at different growth stages. Result obtained from the present study indicate that the influence of environmental and soil factors on nodulation can be reduced by inoculating thee young seedlings with rhizobial before planting.

The study conclude that the influence of environmental and soil factors on nodulation can be reduced by inoculating the young seedlings with rhizobial before planting.

\section{REFERENCES}

1. Bras C.P., Paink H.P.S and Sturman,N., 2000.Structure and function of nod factors,.In;Prokaryotic nitrogen fixation: a model system for the analysis of a biological process. Horizon scientific press.365-383.

2. Chandra R., 1991. Influence of different level of Rhizobium inoculums and phosphorus on nodulation.Dry matter production and yield of Lentil Legume Research.14[3].143-149.

3. Gandhi M.B and Godbole S.H.,1990. Effect of fast growing Rhizobia from wild legumes on Vigno unguiculata [L] Walp. Indian J.Expt.Biol., 28:438-440

4. Ghalab N.N.M.A., Hadity,F.M., and Abotalevb,H.H.Y., 2000.Rhizobial inoculation of guar plant and its effect on growth,nodulation and biological nitrogen fixation. Annals of Agricultural science-Cairo45 (1) 79-90.

5. Kulhare P.S., Podihar S.K.,Khan R.A., 1996.Effect of biofertilizers on soybean under Tawa common area.Advances in Agricultural Research.22-27.

6. Lazzo F.B. and Wopereis J.L.,2000.Unraveling the infection process in Rhizobium-legume symbiosis by microscopy. In:E.W.Triplett. Prokaryotic nitrogen fixation:a model system for the analysis of a biological process .Horizon scientific press, 295-347

7. Poonam Chaudhary,Khurana,A.L., and Dudeja S.S., 2002.Heterogeneity of rhizobia isolated from chick pea nodulation variants.Indian J.Microbial.42:195-199

8. Poornina Yada., 2004.Importance of Blue-green algae in Agricultural.Kissan world.23-24.

9. Vincent I.M., 1970. A Manuaal for the practical study of root nodule bacteria.Blackweall scientific publications, Oxford.IBP Hand book NO.15.

10. Yousif A.N., and sprent J.J,1983. Effect of NaCll on growth,nitrogen incorporation and chemical composition of inoculated and NH4NO3 fertilized Vicia faabaL.Jr.Exp.Bot.34:941-950. 
TABLE-1: Biochemical characteristics of Rhizobial isolates for Vigno mungo L.

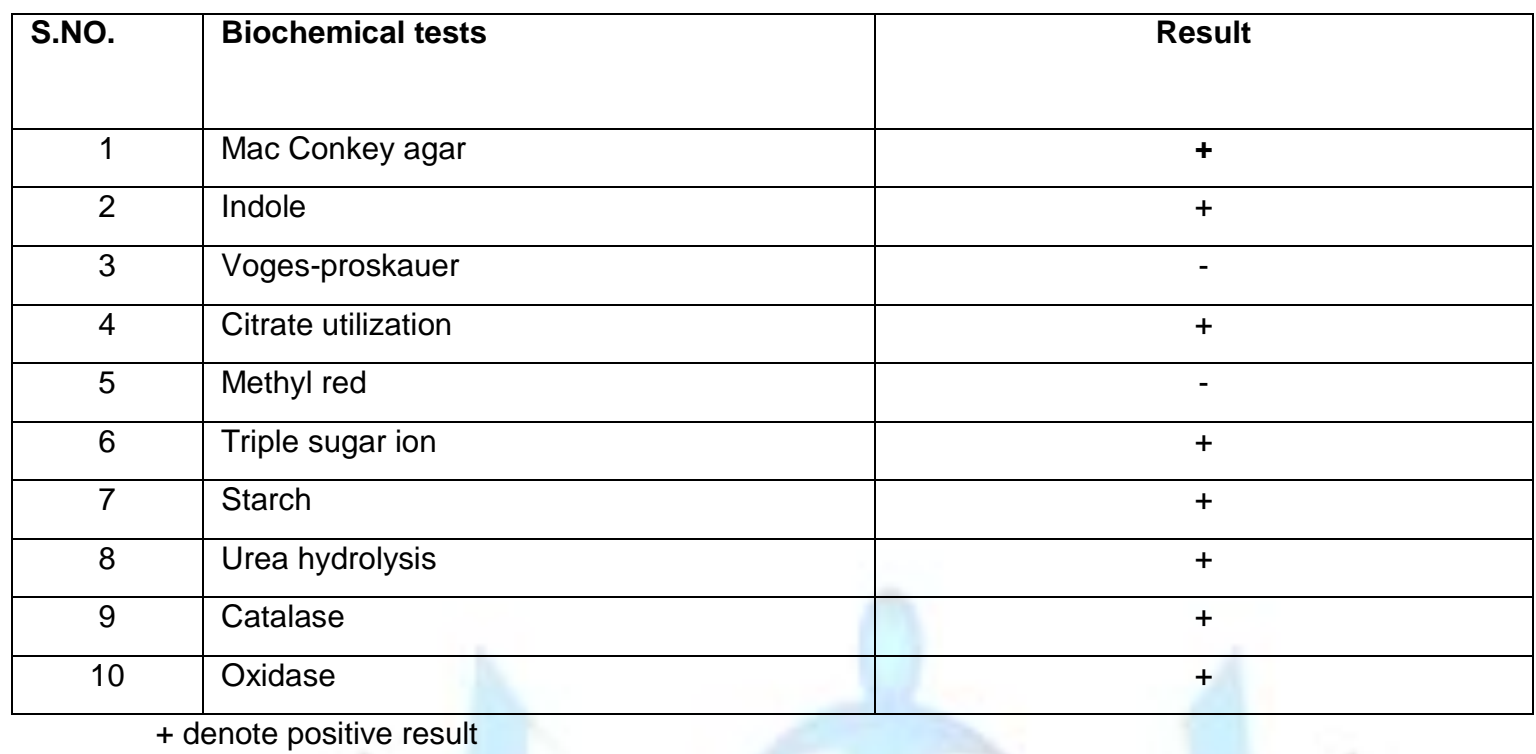

Table-2: Mass production of Rhizobium

\begin{tabular}{|c|c|c|c|}
\hline \multicolumn{4}{|c|}{ Total number of nodules } \\
\hline \multicolumn{4}{|c|}{ Total number of root nodules } \\
\hline \multirow[t]{2}{*}{ Day after planting } & \multirow[t]{2}{*}{ Control plants } & \multicolumn{2}{|c|}{ Rhizobium inoculated plants } \\
\hline & & Seed inoculated & Radical inoculated \\
\hline 20 & 0 & 0 & 2 \\
\hline 30 & 4 & 4 & 6 \\
\hline 40 & 8 & 11 & 13 \\
\hline 50 & 12 & 18 & 25 \\
\hline \multicolumn{4}{|c|}{ Total biomass production } \\
\hline Day after planting & Control plants & Seed inoculated & Radical inoculated \\
\hline 20 & 20 & 20 & 25 \\
\hline 30 & 55 & 62 & 78 \\
\hline 40 & 70 & 78 & 108 \\
\hline 50 & 85 & 96 & 115 \\
\hline \multicolumn{4}{|c|}{ Root biomass in control } \\
\hline Day after planting & Control plants & Seed inoculated & Radical inoculated \\
\hline 20 & 10 & 05 & 10.5 \\
\hline 30 & 15 & 10 & 18 \\
\hline 40 & 20 & 18 & 28 \\
\hline 50 & 40 & 25 & 36 \\
\hline
\end{tabular}

